\title{
Failure analysis of transmission line tower subjected to combined wind and dust loads
}

\author{
Shaik Esub Salaam ${ }^{1}$, N. Prasad Rao ${ }^{2, *}$ and P. Krishnam Raju ${ }^{1}$ \\ ${ }^{1}$ Department of Civil Engineering, Gayatri Vidya Parishad College of Engineering (Autonomous), Madhurawada, Visakhapatnam 530048 , India \\ ${ }^{2}$ CSIR-Structural Engineering Research Centre, Chennai 600 113, India
}

Towers play a vital role in the transmission line (TL) system. The main objective of the present study is to analyse the failure of towers subjected to dust storms. This study, analyses the failure of a $765 \mathrm{kV}$ singlecircuit delta-type horizontal configuration tower in the river delta region near Agra. TL towers are designed based on IS 802 Part 1/Sec 1 and 2 standards. Dust particles of soil may be lighter individually, but have definite density. The wind carrying dust particles may increase the wind pressure on the tower line system. The increased wind pressure significantly affects the sag and tension of ground wire and conductor and results in additional loads on the tower, thus causing failure. It also increases wind load on the tower body and insulator string. There is literature related to numerical and wind tunnel studies on the combined effect of wind and rain loads, but no information is available on the wind and dust loads at present. The density variation method is used in the present study for calculation of additional wind pressure due to dust particles during storms. A relation between density of air mix, volume fraction of dust and density of dust particles is considered. Using FEM software, the tower is analysed for existing design loads and verified for its strength adequacy. The tower stability is studied by analysing for additional loads considering the presence of dust particles in the wind for three different volume fractions of $0.01 \% / \mathrm{m}^{3}, 0.02 \% / \mathrm{m}^{3}$ and $0.03 \% / \mathrm{m}^{3}$. The wind pressure increases by about $10 \%$ for an increase of every $0.01 \%$ of dust particles in the wind. The tension in the conductor and ground wire increases by $8 \%$. The existing tower design is inadequate to withstand the additional forces from wind storms associated even with a small fraction of dust particles and may be the reason for the failure of towers in northern India during a particular period of the year.

Keywords: Dust storms, failure analysis, power supply, transmission line towers.

TRANSMISSION LINE (TL) towers play a vital role in the power transmission system. Full-scale testing of TL towers is mandatory throughout the world. The tower design depends on ultimate stresses and the loads are based on the reliability/return period concept. A dust storm is a meteorological phenomenon common in arid and semi-

*For correspondence. (e-mail: nprao@serc.res.in) arid regions. Westerly winds typically bring loose sand and soil particles from the Arabian Peninsula or Thar Desert in northwestern India to the Indo-Gangetic Plains (IGP) from March to May, the pre-monsoon season. Dust storms commonly occur in the IGP stretching from the western state of Rajasthan to the eastern state of Uttar Pradesh. The dust storm which occurred in 2018 was more devastating than the previous one as the weather system carried more dust and resulted in the collapse of 19 towers in the $765 \mathrm{kV}$ line and 11 towers in the 400 and $220 \mathrm{kV}$ lines across the three northern states. In 2014, around $30 \mathrm{TL}$ towers failed in north India during a dust storm. The failure rate was much higher (55-70\%) in suspension-type than in tension-type towers; this may be due to cascading effect of the failure of the suspension tower and secondary failure of adjacent suspension towers due to the pulling force of conductors developed due to failure. In most cases, the utilities point to the highintensity wind as the cause for tower failures, but not able to substantiate due to non-availability of exact wind data at failure location. It indicates the fragility of the grid infrastructure against dust storms. The combined effect of wind and dust loads on TL towers has not been studied either numerically or in a wind tunnel. Additional wind pressure due to the presence of dust particles is predicted by modifying the air density.

The density of air combined with dust particles is equal to air density plus volume fraction of dust particles multiplied by its density. Geographical data indicate sandy loam deposits are dominant in the IGP with a density of $1460 \mathrm{~kg} / \mathrm{m}^{3}$. The wind associated with the dust particles increases the wind pressure and thereby load on the tower. Figure 1 shows the recent failure of a $765 \mathrm{kV}$ TL tower during a dust storm. In the present study, a $765 \mathrm{kV}$ tower has been considered in detail for the additional wind loads due to wind carrying the dust particles. The member forces and the capacity predicted using Indian design standards have been compared. The increase in member forces and its effect on the stability of the tower are studied.

\section{Literature review}

$\mathrm{Fu}$ and $\mathrm{Li}^{1}$ presented a methodology for conductor load calculation due to combined wind and rain, and concluded 


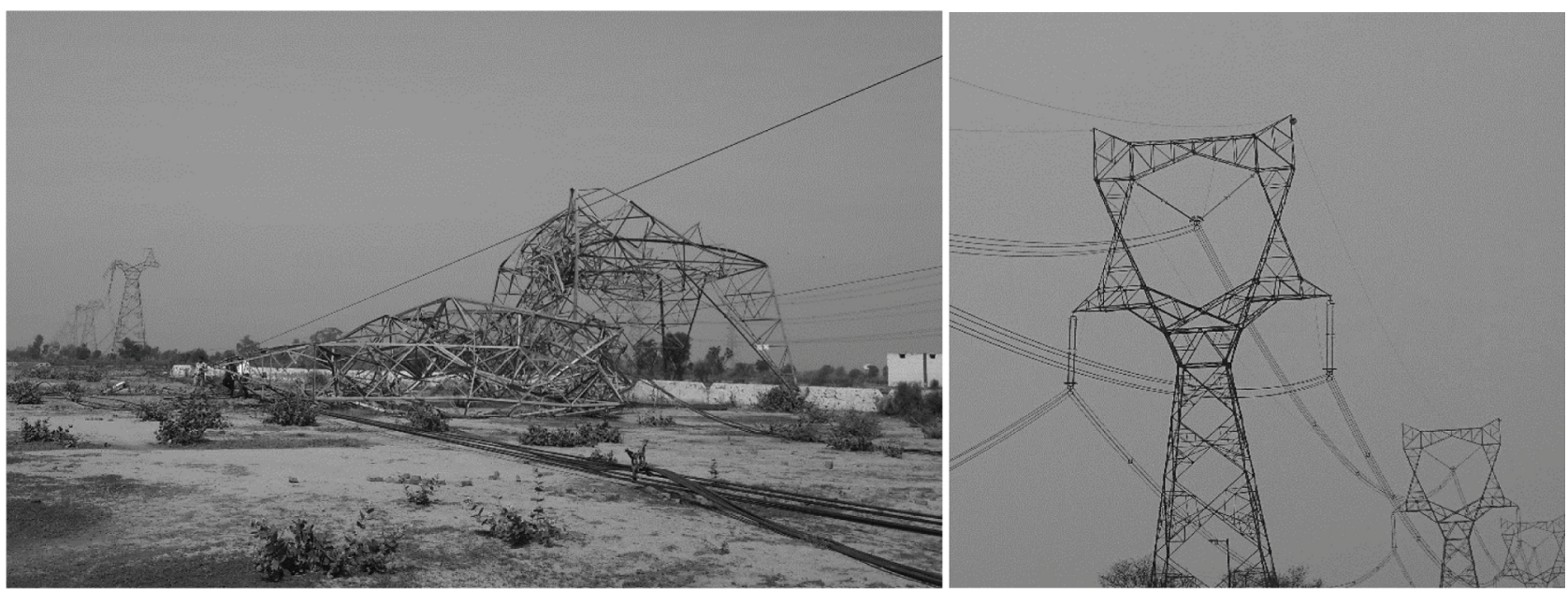

Figure 1. Collapsed and intact $765 \mathrm{kV}$, single-circuit, delta-type transmission tower.

that the effect of rain load is significant. Drag coefficient accounting for the combined effect of wind and rain loads was derived based on wind tunnel test results ${ }^{2}$. The failure mechanism of a $110 \mathrm{kV}$ TL tower that failed during a super typhoon in China due to wind and rain loads was studied by An et al. ${ }^{3}$. Dynamic analysis on four-span TL system subjected to typhoon wind and rain loads was performed, and it was concluded that axial force increases up to $12 \%$. Zhang and $\mathrm{Xie}^{4}$ studied a $220 \mathrm{kV}$ river-crossing suspension tower that had failed under strong wind loads by performing static nonlinear and dynamic analysis to predict the most vulnerable panels of the tower, and emphasized the importance of dynamic analysis. The nonlinear static pushover analysis technique predicts the actual load factor and plastic hinge formation on towers subjected to wind load ${ }^{5}$ Fu et al. $^{6}$ studied TL towers under the action of extreme wind load by conducting the fullscale test on a $230 \mathrm{kV}$ suspension tower and developed a uniform imperfection mode method to estimate strength capacity.

The wind with rainfall causes collapse at a lower basic wind speed than pure wind condition. The rainfall effect becomes increasingly significant with increasing number of bundle conductors ${ }^{7}$. Rain load has a substantial effect on the dynamic response of transmission tower-line systems. A raindrop impinging process exhibits both positive and negative forces and the peak values are of the same order of magnitude ${ }^{8}$. Tian et al. ${ }^{9}$ conducted a wind-induced collapse analysis of long-span TL system considering the member buckling effect. The interaction between bending moment and shear deformation was found to be critical to the collapse of a tower'.

Dynamic analyses on a TL system with three towers and four spans after an insulator breakage under ice load showed that a higher ice load can lead to more severe vibration. Insulator breakage in higher span lengths can result in the cascading collapse of the TL system ${ }^{10}$.
Tian et al. ${ }^{11}$ proposed a procedure for simulating the failure process based on the full-scale tests on TL towers subjected to various loading patterns. The multi-scale finite element (FE) method using shell elements to model the potential local failure areas and beam elements to model other parts can effectively simulate stress concentration around the bolt connections and cross-section plastic collapse of the critical structural members ${ }^{12}$. Nonlinear static pushover analysis on existing TL towers under wind loading indicated that the collapse mechanism differing from the intended goals of the code for developing a significant inelastic response in a large number of elements instead showed a local concentration of the damage with non-uniform distribution of yielding within the height ${ }^{13}$.

$\mathrm{Fu}$ et al $^{14}$ proposed a methodology based on the equivalent basic wind speed concept for fragility analysis of towers subjected to wind and rain load. They concluded that the rain load contributes significantly to tower collapse $^{14}$. The capacity curve for a tower within the TL can be determined adequately by conducting a nonlinear static pushover analysis on a single tower ${ }^{15}$. Studies on progressive collapse vulnerability of a $400 \mathrm{kV}$ tower in a TL system showed that it may resist the progressive collapse due to possible alternative load paths ${ }^{16}$.

Strong wind and rain load significantly affect the reliability of the transmission line system ${ }^{17}$. The influence of rain load cannot be ignored on the TL tower during strong rainstorm ${ }^{18}$. Xie and Sun $^{19}$ conducted an experimental study on two pairs of sub-assemblages consisting of single and double panels, similar to the $500 \mathrm{kV}$ tower damaged during an ice disaster with and without diaphragm bracing. The diaphragm bracing increased the ultimate strength by $18.3 \%$ and $17.6 \%$ for the single- and double-panel tower sub-assemblages respectively ${ }^{19}$.

The basic wind speed depends on peak gust velocity averaged over a short time interval of about $3 \mathrm{sec}$ (ref. 20). 


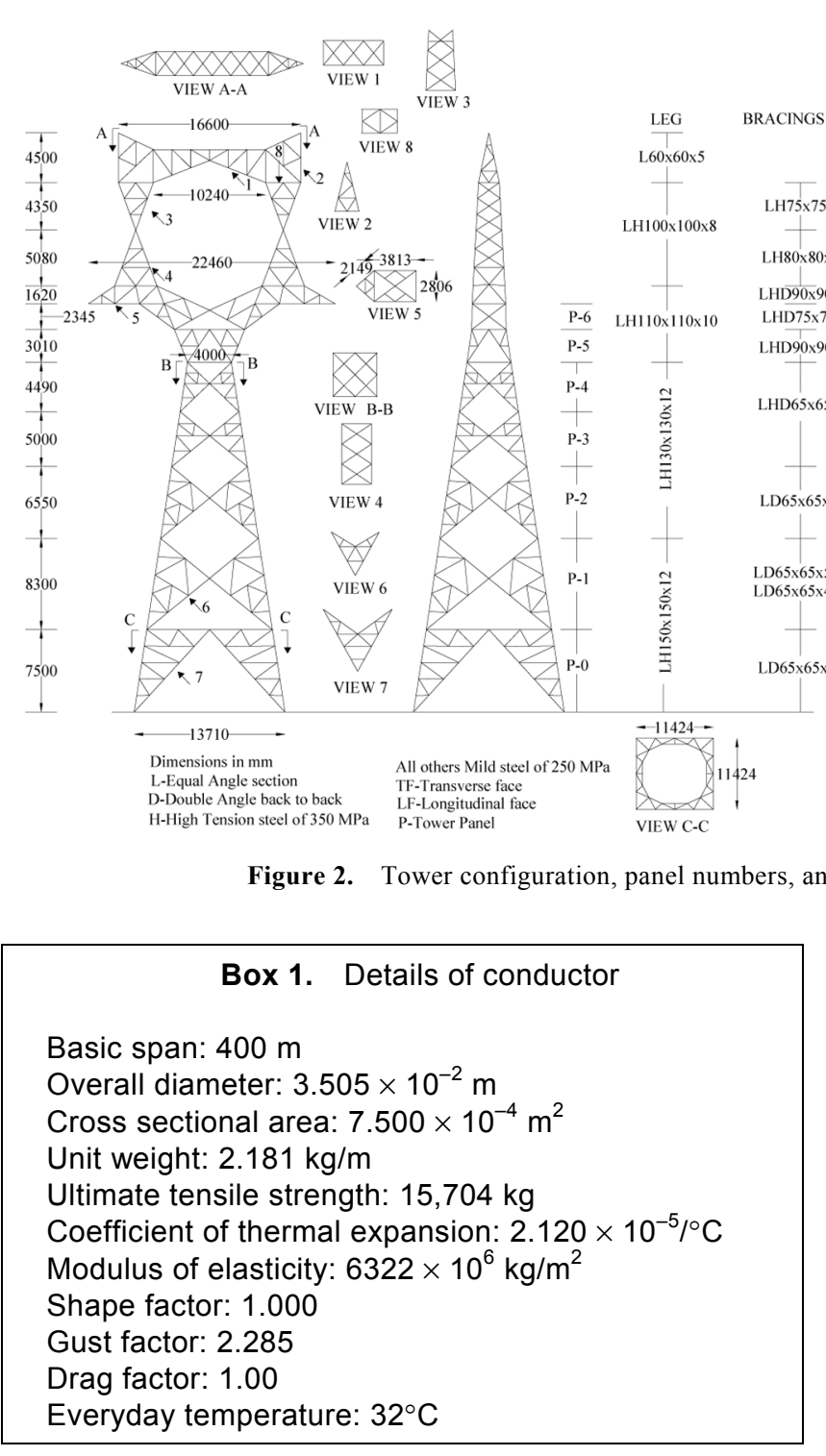

Box 2. Details of ground wire

Basic span: $400 \mathrm{~m}$

Overall diameter: $1.098 \times 10^{-2} \mathrm{~m}$

Cross sectional area: $7.362 \times 10^{-4} \mathrm{~m}^{2}$

Unit weight: $0.583 \mathrm{~kg} / \mathrm{m}$

Ultimate tensile strength: $6972 \mathrm{~kg}$

Coefficient of thermal expansion: $1.150 \times 10^{-5} /{ }^{\circ} \mathrm{C}$

Modulus of elasticity: $19361 \times 10^{6} \mathrm{~kg} / \mathrm{m}^{2}$

Shape factor: 1.000

Gust factor: 2.3865

Drag factor: 1.20

Everyday temperature: $32^{\circ} \mathrm{C}$

TL towers are designed for meteorological reference wind speed derived by converting the $3 \mathrm{sec}$ peak gust speed into 1 minute averaging period using a factor ${ }^{21}$. Towers are designed for three reliability levels based on voltage clause. The members are designed based on ulti- mate stresses. Eccentricity and end restraints in compression member design are accounted by considering the modified slenderness ratio ${ }^{22}$.

The literature review shows that the combined effect of wind and dust storms on the TL tower system has not been studied numerically using wind tunnel experiments. In recent years, there is frequent occurrence of dust storms over north India during the pre-monsoon season, causing severe damage to the TL system according to the major power distributors, even though the measured wind speeds are less than the design wind speed. Hence there is a need for studying the effect of dust storms on the stability of the TL system subjected to the combined action of wind and dust.

\section{Tower configuration}

In recent years, there is failure of TL towers of different voltage clauses in the northwestern India. For the present study, a single-circuit, delta-type horizontal configuration tower which collapsed in the $765 \mathrm{kV}$ TL system in northwestern India has been considered. The $765 \mathrm{kV}$ line was commissioned in Agra region after the successful completion of full-scale testing and presently in use. The square-based tower is $52.75 \mathrm{~m}$ in height, $13.71 \mathrm{~m}$ wide at $+0 \mathrm{~m}$ level and $4 \mathrm{~m}$ wide at $32 \mathrm{~m}$ hamper level. An IVI conductor configuration is used with 'I-string' for the left and right conductors, and ' $\mathrm{V}$-string' for the middle conductor. Two ground wire systems are provided. Figure 2 shows the tower configuration, dimensions, panel number, FE model and loading on a tower. Boxes 1 and 2 provide details of the conductor and ground wire used. 


\section{Wind load}

\section{Sag and tension}

Sag is the vertical distance between the support points and the lowest point of a conductor. The horizontal distance between the wire supports is called the span of the wire. In TL towers, the significant loads are from the normal and broken conductor conditions. Sag and tension for conductor and ground wire are calculated according to IS 802 (Part 1/Sec 1): 2015 (ref. 21) and CBIP (Central Board of Irrigation and Power) Manual 2014. Sag and tension depend on several factors such as wind pressure, unit weight of wire, thickness, initial tension in the wire, temperature and material properties of wire, etc.

$$
S=\frac{w L^{2}}{8 T}
$$

where $S$ is the sag of wire $(\mathrm{m}), w$ the unit weight of the wire $(\mathrm{kg} / \mathrm{m}), L$ the length of the wire $(\mathrm{m})$ and $T$ is the final tension in the wire $(\mathrm{kg})$.

Table 1 shows the sag and tension in the conductor and ground wire for the existing design loads. The maximum sag and tension in the ground wire are $11.466 \mathrm{~m}$ and $3770 \mathrm{~kg}$ and in conductor $14.835 \mathrm{~m}$ and $9668 \mathrm{~kg}$ respectively, for the existing design wind pressure.

Table 1. Design sag and tension in conductor and ground wire $(\mathrm{GW})$

\begin{tabular}{lrrrc}
\hline Temperature $\left({ }^{\circ} \mathrm{C}\right)$ & $P_{\mathrm{d}}\left(\mathrm{kg} / \mathrm{m}^{2}\right)$ & Wind & Sag $(\mathrm{m})$ & Tension \\
\hline Conductor & & & & \\
32 & 89.6 & 100 & 4.512 & 9668 \\
85 & 89.6 & 0 & 14.835 & 2940 \\
$\mathrm{GW}$ & & & & \\
32 & 89.6 & 100 & 3.093 & 3770 \\
53 & 89.6 & 0 & 11.466 & 1017 \\
\hline
\end{tabular}

Table 2. Load on tower panels

\begin{tabular}{lc}
\hline Panel no. & Transverse load $(\mathrm{kg})$ \\
\hline P-0 & 5871 \\
P-1 & 4779 \\
P-2 & 3238 \\
P-3 & 2309 \\
P-4 & 2028 \\
P-5 & 1148 \\
P-6 & 834 \\
\hline
\end{tabular}

Table 3. Design load on conductor and GW

\begin{tabular}{lrrrrrrr}
\hline & \multicolumn{3}{c}{ Normal condition $(\mathrm{kg})$} & & \multicolumn{3}{c}{ Broken condition $(\mathrm{kg})$} \\
\cline { 2 - 3 } \cline { 7 - 8 } Wire type & \multicolumn{1}{c}{ TL } & VL & LL & & TL & VL & LL \\
\hline Conductor & 13,361 & 6,234 & 0 & & 6,114 & 4,141 & 15,757 \\
GW & 1,259 & 360 & 0 & & 561 & 220 & 3,073 \\
\hline
\end{tabular}

TL, Transverse load; VL, Vertical load; LL, Longitudinal load.

\section{Wind load on tower body}

The wind load on the tower is calculated based on IS 802 (Part 1/Sec 1): 2015 specifications ${ }^{21}$. As shown in Figure 2, the tower is divided into panels. Wind load on each panel is calculated and distributed at the corner nodes of the corresponding panel. Table 2 gives the transverse wind load on the tower for design wind pressure. A well-designed TL tower should withstand transverse and longitudinal loads from the conductor and ground wire. Generally, loads on the tower are calculated for normal and broken wire conditions under different categories like reliability, security and safety requirements. Table 3 gives the loads on the conductor and ground wire under reliability and security requirements.

\section{Finite element analysis}

NE-NASTRAN, FE analysis software has been used to study the failure of the tower in detail. The tower members are modelled using beam elements with four sub-elements per member. The beam element is a line element with a defined shape and with stress recovery points. The limit load is reached in FE analysis when the stresses at the maximum stressed point in the member exceed the yield stress. Nonlinear analysis accounting for geometric and material nonlinearity is performed on the tower. The elastic and plastic material property of steel is represented by an elastoplastic bi-linear model with the modulus of elasticity as 2E5 MPa up to yield level and $2000 \mathrm{MPa}$ above yield level. Figure 2 shows the FE model, while Figure 3 shows the schematic diagram of conductor and ground wire points for all critical load combinations considered in the present study. The tower was analysed for all critical design load combinations given in Box 3 . Table 4 shows the FE model analysis force in the leg and bracing members for the design loads. The member forces are compared with the design strength.

\section{Design of tower members (elements)}

The tower members are designed based on IS 802 (Part 1/ Sec 2): 2016 specifications $^{22}$, which are in line with 'Design

Box 3. Critical load cases

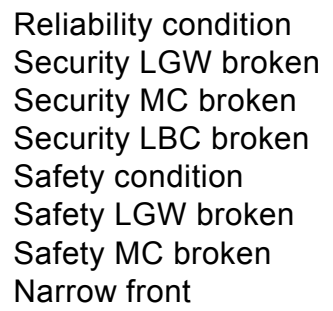



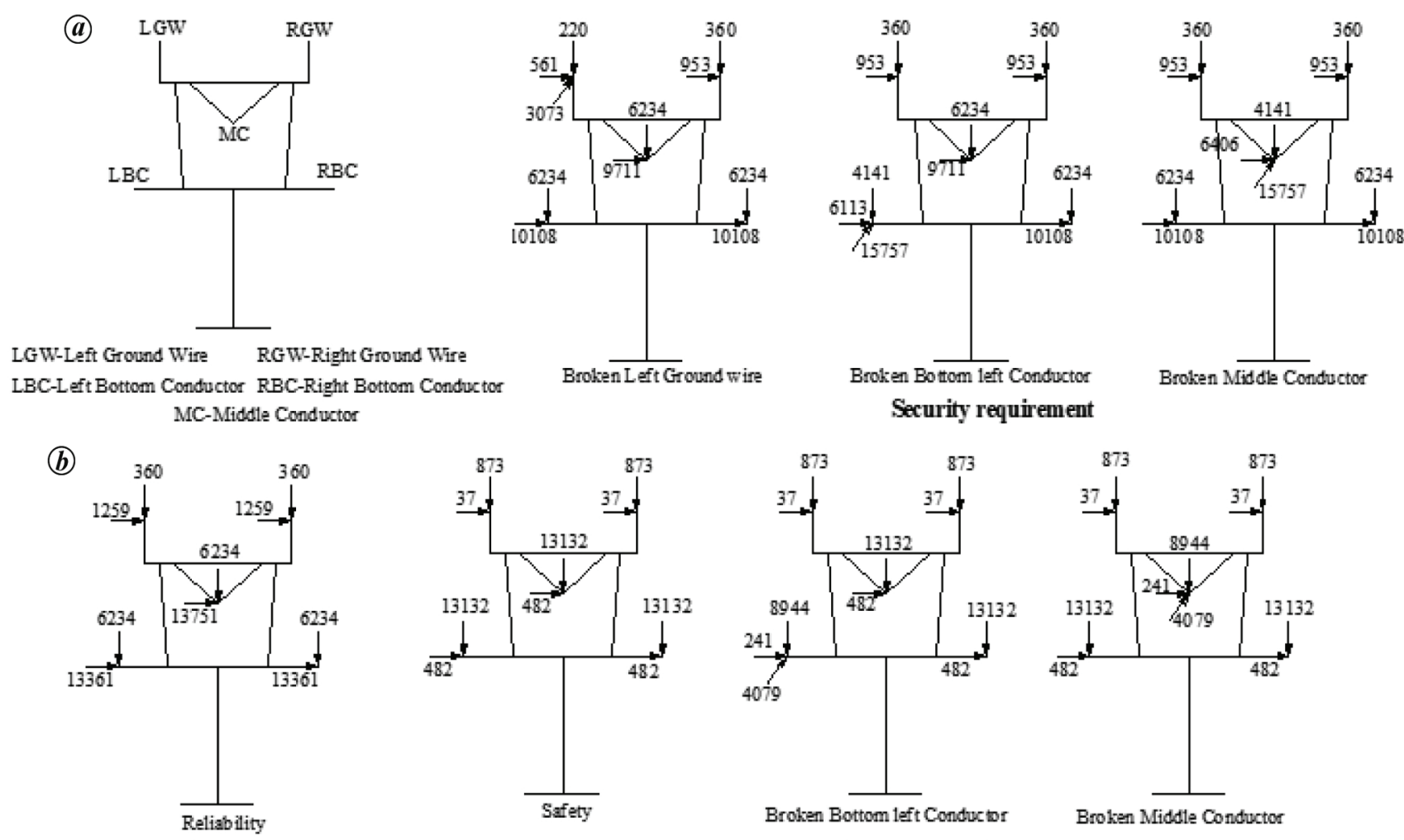

Reliability requirement
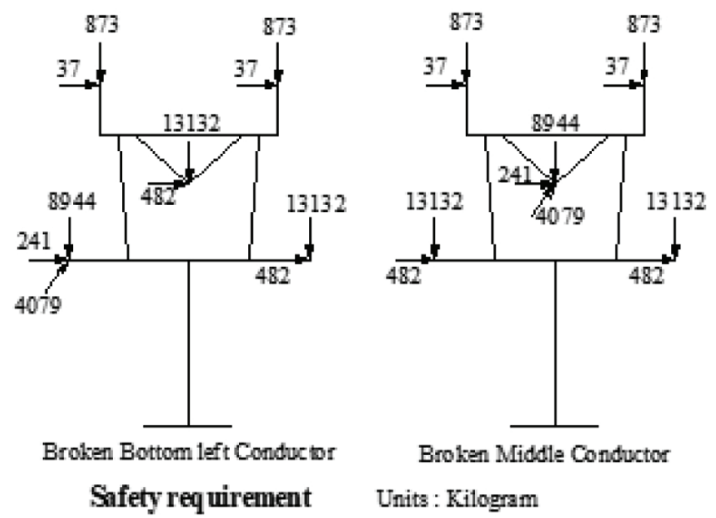

Figure 3. $\boldsymbol{a}$, Schematic view of conductor and ground wire. $\boldsymbol{b}$, Load trees: design load for critical load combinations.

Table 4. Analysis of forces in leg and bracing members (design load)

\begin{tabular}{|c|c|c|c|}
\hline Member size (mm) & $\begin{array}{l}\text { Yield stress } \\
\left(\mathrm{N} / \mathrm{mm}^{2}\right)\end{array}$ & $\begin{array}{l}\text { Slenderness } \\
\text { ratio }\end{array}$ & $\begin{array}{l}\text { Member force }(\mathrm{kN}) \\
0 \% \text { of dust particles }\end{array}$ \\
\hline \multicolumn{4}{|l|}{ Leg members } \\
\hline $\mathrm{L} 150 \times 150 \times 12$ & 350 & 51 & 983 \\
\hline $\mathrm{L} 130 \times 130 \times 12$ & 350 & 52 & 901 \\
\hline $\mathrm{L} 110 \times 110 \times 10$ & 350 & 76 & 632 \\
\hline $\mathrm{L} 100 \times 100 \times 8$ & 350 & 93 & 205 \\
\hline \multicolumn{4}{|l|}{ Bracing members } \\
\hline $\mathrm{T} 65 \times 65 \times 5$ & 250 & 120 & 98 \\
\hline $\mathrm{T} 65 \times 65 \times 4$ & 250 & 121 & 66 \\
\hline $\mathrm{T} 65 \times 65 \times 5$ & 350 & 106 & 169 \\
\hline $\mathrm{T} 90 \times 90 \times 6$ & 350 & 90 & 105 \\
\hline $\mathrm{T} 75 \times 75 \times 5$ & 350 & 89 & 93 \\
\hline $\mathrm{T} 90 \times 90 \times 7$ & 350 & 95 & 121 \\
\hline
\end{tabular}

L, Equal angle section; T, Back to back angle section.

of lattice steel transmission structures, ASCE 10-15, standard $^{23}$. The effective length of the compression member depends on the eccentricity and end restraint. Based on the end conditions, loading eccentricity and member slenderness ratio, a detailed procedure for modification of slenderness ratio and member stresses accounting for the local plate buckling of angle sections is given in the code. Table 5 shows the capacity of leg and bracing members.

\section{Wind pressure due to dust particles in wind}

Guidelines or methodology for calculating the wind pressure on towers subjected to combined wind and dust loads are not available in the literature. In the present study, the density variation method has been adopted for calculating the additional wind pressure due to presence of various percentages of dust particles in the dust storms. The relation between density of air, density of air mixed with dust particles and volume of dust fraction is used.

$$
r_{\text {air mix }}=r_{\text {air }}+V_{\mathrm{f}} * r_{\text {dust particles }} \text {, }
$$

where $r_{\text {air mix }}$ is the density of air with dust particles or increased air density due to dust particles $\left(\mathrm{kg} / \mathrm{m}^{3}\right), r_{\text {air }}$ the density of air $\left(\mathrm{kg} / \mathrm{m}^{3}\right), V_{\mathrm{f}}$ the volume fraction $/ \mathrm{m}^{3}, r_{\text {dust particles }}$ is the density of dust particles.

The design wind pressure at any height above the mean ground level can be calculated using the relation between wind pressure and wind speed as given in IS 875 (Part 3): 2015 (ref. 20).

$$
P=\frac{1}{2} r * V^{2}
$$

where $P$ is the wind pressure $\left(\mathrm{N} / \mathrm{m}^{2}\right), r$ the density of air $\left(\mathrm{kg} / \mathrm{m}^{3}\right)$ and $V$ is the design wind velocity $(\mathrm{m} / \mathrm{s})$. 

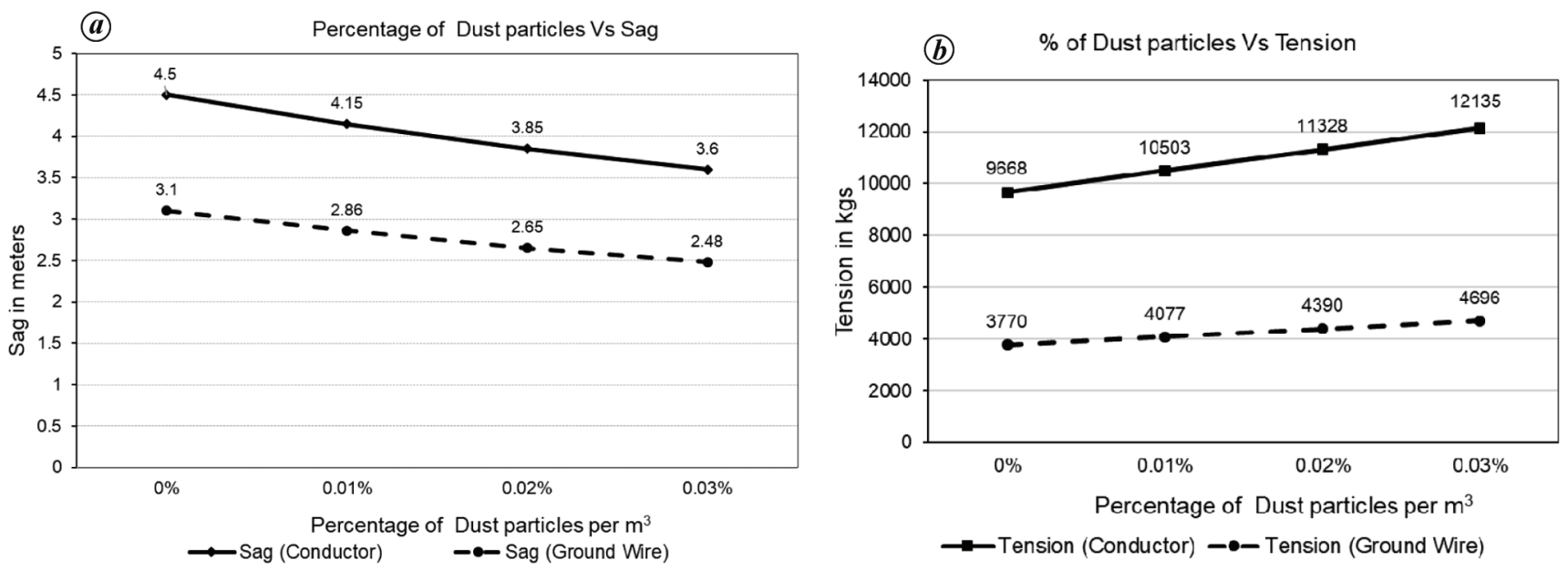

Figure 4. Variation of (a) sag and (b) tension in conductor and ground wire for different fractions of dust particles.

Table 5. Capacity of leg and bracing members

\begin{tabular}{|c|c|c|c|c|}
\hline Member size (mm) & $\begin{array}{l}\text { Yield strength } \\
\left(\mathrm{N} / \mathrm{mm}^{2}\right)\end{array}$ & $\begin{array}{c}\text { Panel } \\
\text { number }\end{array}$ & $\mathrm{KL} / \mathrm{r}$ & $\begin{array}{c}\text { Capacity } \\
(\mathrm{kN})\end{array}$ \\
\hline \multicolumn{5}{|l|}{ Leg members } \\
\hline \multirow[t]{2}{*}{$\mathrm{L} 150 \times 150 \times 12$} & 350 & $\mathrm{P}-0$ & 51 & 1051 \\
\hline & & P-1 & 57 & 1020 \\
\hline \multirow[t]{3}{*}{$\mathrm{L} 130 \times 130 \times 12$} & 350 & $\mathrm{P}-2$ & 52 & 918 \\
\hline & & P-3 & 55 & 900 \\
\hline & & $\mathrm{P}-4$ & 51 & 922 \\
\hline \multirow[t]{2}{*}{$\mathrm{L} 110 \times 110 \times 10$} & 350 & P-5 & 76 & 549 \\
\hline & & P-6 & 75 & 549 \\
\hline $\mathrm{L} 100 \times 100 \times 8$ & 350 & P-7 & 93 & 551 \\
\hline \multicolumn{5}{|l|}{ Bracing members } \\
\hline $\mathrm{T} 65 \times 65 \times 4$ & 250 & $\mathrm{P}-0$ & 110 & 140 \\
\hline $\mathrm{T} 65 \times 65 \times 5$ & 250 & P-1 & 120 & 169 \\
\hline $\mathrm{T} 65 \times 65 \times 4$ & 250 & $\mathrm{P}-2$ & 108 & 143 \\
\hline $\mathrm{T} 65 \times 65 \times 5$ & 350 & P-3 & 115 & 131 \\
\hline $\mathrm{T} 65 \times 65 \times 5$ & 350 & P-4 & 94 & 253 \\
\hline $\mathrm{T} 90 \times 90 \times 7$ & 350 & P-5 & 90 & 416 \\
\hline $\mathrm{T} 75 \times 75 \times 5$ & 350 & P-6 & 89 & 273 \\
\hline $\mathrm{T} 90 \times 90 \times 7$ & 350 & P-7 & 95 & 492 \\
\hline
\end{tabular}

$\mathrm{KL} / \mathrm{r}$, Effective slenderness ratio.

Table 6. Variation of wind pressure

\begin{tabular}{lcc}
\hline $\begin{array}{l}\text { Volume fraction } \\
\text { of dust }\left(V_{\mathrm{f}}, \%\right)\end{array}$ & $\begin{array}{r}r_{\text {air mix }} \\
\left(\mathrm{kg} / \mathrm{m}^{3}\right)\end{array}$ & $\begin{array}{r}\text { Wind pressure } \\
\left(\mathrm{kg} / \mathrm{m}^{2}\right)\end{array}$ \\
\hline 0 & 1.200 & 89.64 \\
0.01 & 1.346 & 100.41 \\
0.02 & 1.492 & 111.30 \\
0.03 & 1.638 & 122.19 \\
\hline
\end{tabular}

Therefore, wind pressure depends on the density of air and velocity of the wind. In the present study, considering the density of air as $1.2 \mathrm{~kg} / \mathrm{m}^{3}$, the density of air combined with dust particles has been studied. Volume fractions of $0 \%, 0.01 \%, 0.02 \%$ and $0.03 \%$ of dust particles in air are considered for wind pressure calculations. Since the density of dust particles (loose-dry soil) is high compared to the density of air, minute fractions of dust particles bring significant change in wind pressure. The geological data indicate the presence of sandy loam soil in the river delta region. The density of sandy loam soils is considered as $1460 \mathrm{~kg} / \mathrm{m}^{3}$ in the calculations. Table 6 shows the variation of wind pressure for different volume fractions. Figure 4 shows the variation of sag and tension in the ground wire and conductors for different percentages of dust particles in air. Since sag and tension are inversely proportional to each other, as the sag decreases, tension increases. Figure 5 shows the variation of wind load on tower body and on insulator string respectively, with changing percentage of dust particles.

As the conductor and ground wire tension increases with increased percentage of dust in air, there is an increase in transverse load and longitudinal load in the conductors and ground wires (Figure 6).

\section{Failure description}

TL towers may fail due to many reasons such as incorrect design assumptions, improper detailing, material defects, fabrication errors, force-fitting during erection, and are classified as local or structural depending on the failure pattern. Failure of primary or secondary bracing not leading to complete collapse is called local failure. Failure due to leg member stress exceeding its capacity is called structural failure. Towers may fail due to failure of the foundation.

The leg member forces predicted from the linear static analysis for $0.01 \%, 0.02 \%$ and $0.03 \%$ of dust particles for the critical load case are compared with the member capacity (Table 7). Figure 7 shows the variation of forces in the leg and bracing members for different fractions of dust in air.

The NL analysis predicts failure of both compression leg members in basic tower level at $94 \%$ load in reliability 


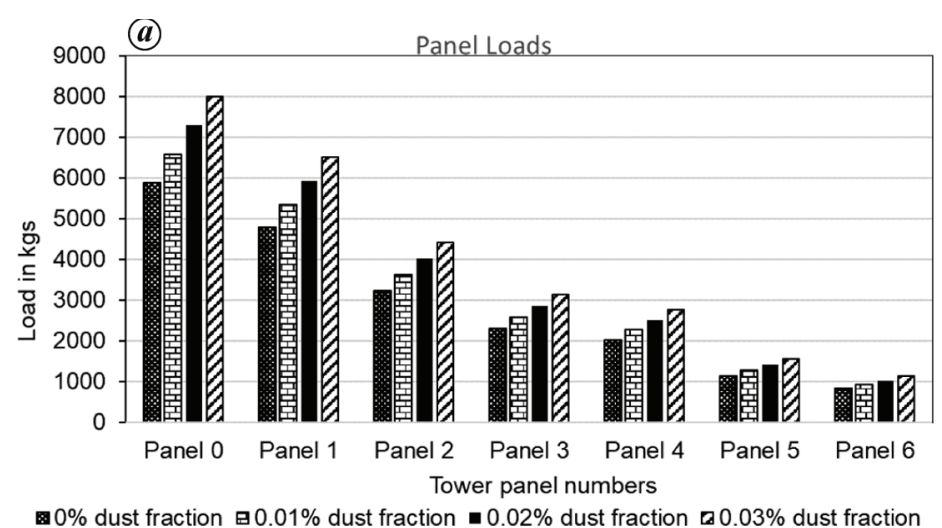

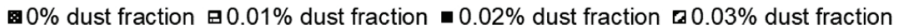

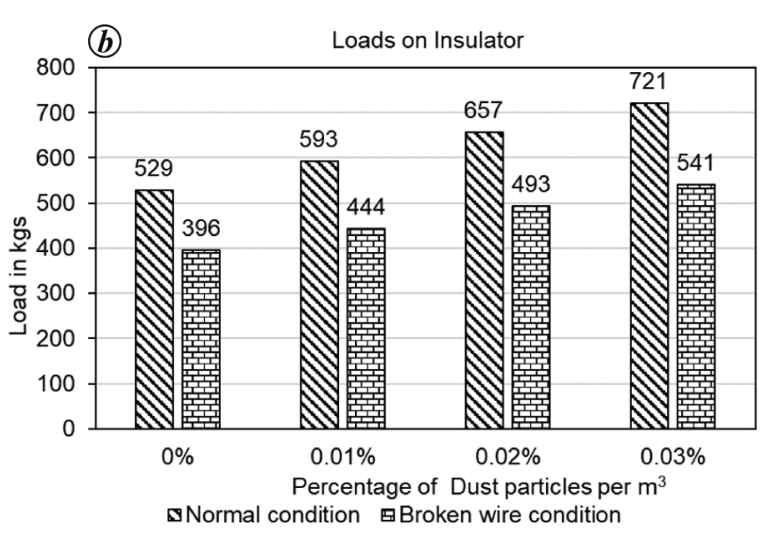

\$Normal condition $\mathrm{gBroken}$ wire condition

Figure 5. Variation of $(\boldsymbol{a})$ tower panel load and $(\boldsymbol{b})$ insulator string for different fractions of dust particles.
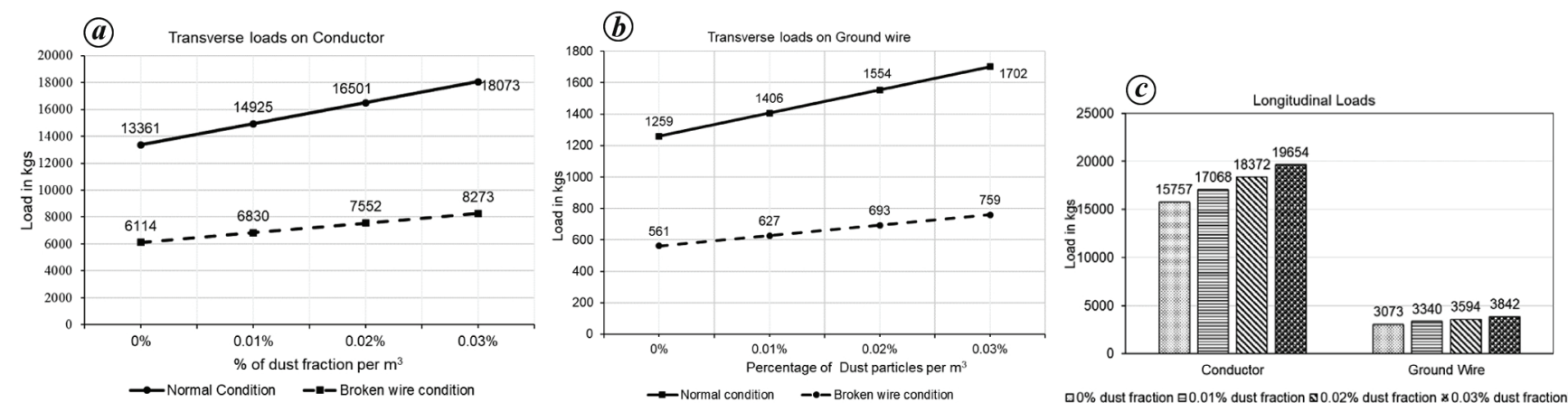

Figure 6. Variation of $(\boldsymbol{a})$ transverse load on conductor and $(\boldsymbol{b})$ ground wire in normal condition (intact) and broken wire condition for different fractions of dust particles. $c$, Variation of longitudinal load on conductor and GW for different fractions of dust particles.

condition with $0.01 \%$ of dust particles (Figure $8 a$ ). Failure occurs due to member stresses exceeding the yield stress. It occurs at the same level for reliability condition with $0.02 \%$ of dust particles at $86 \%$ load (Figure $8 \mathrm{~b}$ ). In the middle conductor broken case with $0.01 \%$ of dust particles, failure occurs at $96 \%$ load due to one leg subjected to stresses above its capacity (Figure $8 c$ ). Right and left conductor broken conditions are less critical for $0.01 \%$ of dust particles compared to $0.02 \%$.

\section{Results and discussion}

\section{Discussion}

Power transmission utilities in northwestern India have reported tower failures during dust storms in the premonsoon period from March to May. The failure rate is much higher $(55-70 \%)$ in suspension-type than tensiontype towers. In the northwestern region, TL towers are designed based on IS 802, considering wind zone 4 under IS 875 with wind speed $47 \mathrm{~m} / \mathrm{s}$. The other localized highintensity wind conditions having narrow front, viz. dust storms/thunderstorms, tornadoes and hurricanes are not considered. The suspension towers are not designed for horizontal forces in the longitudinal direction. Hence the failure of one suspension-type tower may lead to adjacent tower failure.

A detailed study was conducted on the failure of a $765 \mathrm{kV}$ delta-type, single-circuit tower subjected to dust storms in the river delta region of northern India. Wind tunnel and numerical studies on the effects of wind associated with dust particles (dust storms) and methodology to evaluate the loads due to dust storms are not available in the literature. Hence for additional wind pressure calculations, the relationship between density of air mix, volume fraction of dust and density of dust particles was considered. In the present study, $0.01 \%$, $0.02 \%$ and $0.03 \%$ of dust particles $/ \mathrm{m}^{3}$ of air are considered. Variation of sag, tension in conductor and ground wire, wind load on tower body and insulator strings have been studied in detail. The influence of increased wind pressure and the resulting load on the overall performance of the tower have also been studied.

\section{Results}

The significant points observed in the present study are listed below. 

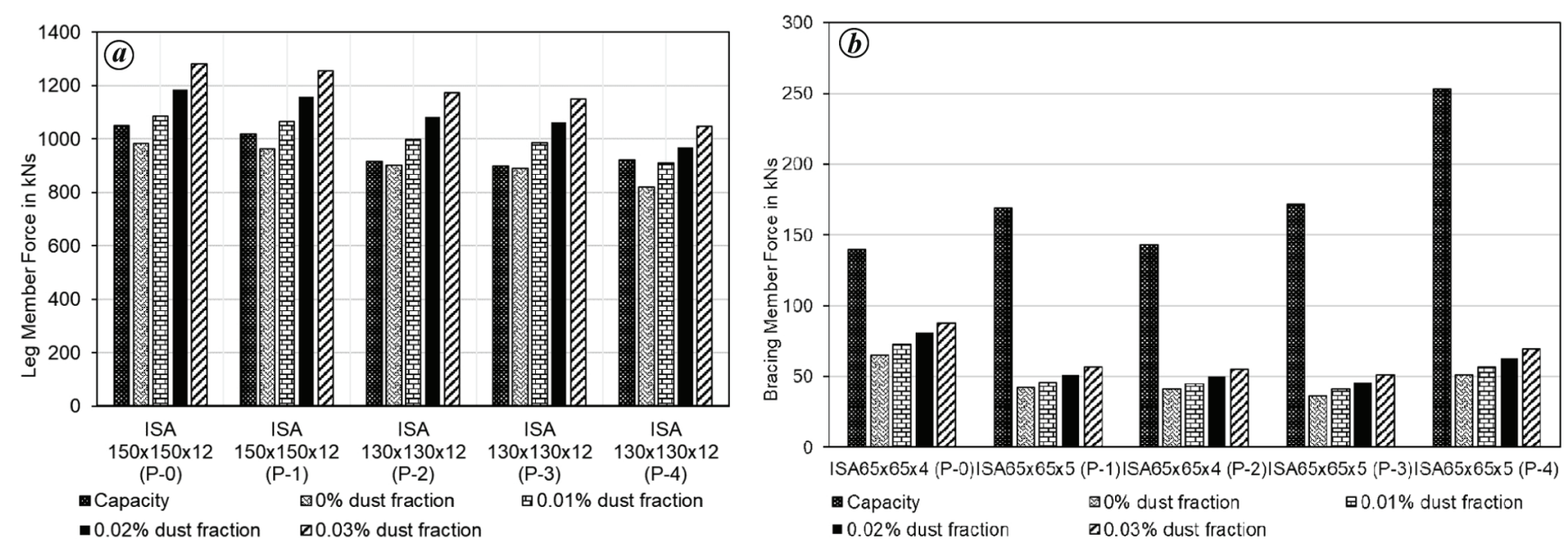

Figure 7. Variation of forces in the $(\boldsymbol{a})$ leg and $(\boldsymbol{b})$ bracing members in different panels of the tower for different fractions of dust particles.

Table 7. Comparison of forces in leg members for different fractions of dust

\begin{tabular}{|c|c|c|c|c|c|c|c|c|}
\hline \multirow[b]{2}{*}{ Leg section $(\mathrm{mm})$} & \multirow{2}{*}{$\begin{array}{l}\text { Yield strength } \\
\left(\mathrm{N} / \mathrm{mm}^{2}\right)\end{array}$} & \multirow{2}{*}{$\begin{array}{c}\text { Panel } \\
\text { number }\end{array}$} & \multirow[b]{2}{*}{$\mathrm{KL} / \mathrm{r}$} & \multirow{2}{*}{$\begin{array}{l}\text { Capacity } \\
(\mathrm{kN})\end{array}$} & \multicolumn{4}{|c|}{$\begin{array}{l}\text { Member force }(\mathrm{kN}) \text { for different } \\
\text { percentages of dust particles in wind }\end{array}$} \\
\hline & & & & & 0 & 0.01 & 0.02 & 0.03 \\
\hline \multirow[t]{2}{*}{$\mathrm{L} 150 \times 150 \times 12$} & 350 & $\mathrm{P}-0$ & 51 & 1051 & 983 & 1087 & 1184 & 1283 \\
\hline & & P-1 & 57 & 1020 & 963 & 1066 & 1159 & 1256 \\
\hline \multirow[t]{3}{*}{$\mathrm{L} 130 \times 130 \times 12$} & 350 & P-2 & 52 & 918 & 902 & 999 & 1083 & 1174 \\
\hline & & P-3 & 55 & 900 & 889 & 986 & 1062 & 1150 \\
\hline & & P-4 & 51 & 922 & 820 & 912 & 969 & 1049 \\
\hline \multirow[t]{2}{*}{$\mathrm{L} 110 \times 110 \times 10$} & 350 & P-5 & 76 & 549 & 439 & 501 & 574 & 625 \\
\hline & & P-6 & 75 & 551 & 386 & 413 & 415 & 431 \\
\hline
\end{tabular}

$\mathrm{KL} / \mathrm{r}$, Effective slenderness ratio; L, Equal angle section.

The wind pressure increases by about $10 \%$ for every $0.01 \%$ increase of dust particles in air $/ \mathrm{m}^{3}$. Since air density increases due to dust particles, wind pressure is directly dependent on air density and velocity.

As wind pressure increases, tension in the ground wire and conductor increases by about $7-8 \%$ for every increase of $0.01 \%$ of dust particles, since the tension is directly dependent on wind pressure. As a result, the transverse load on the conductor and ground wire increases by $11 \%$, and longitudinal load on the conductor and ground wire increase by $7.5 \%$. Transverse load on the tower body and insulators increase by $10 \%$ for every $0.01 \%$ increase of dust particles, since it is directly dependent on wind pressure.

The sag is indirectly proportional to tension. Hence sag in conductor and ground wire decreases by about $8 \%$ for every $0.01 \%$ increase of dust particles. As a result, the leg and bracing member forces increase by about $9.5 \%$ for every $0.01 \%$ increase of dust particles, resulting in overstressing beyond yield level and failure of the tower.

\section{Suggestions for failure prevention}

The towers can be strengthened after identifying the critical members by replacing them with higher size mem- bers, adding redundant members to the main members for increasing compression capacity, and providing hip and plan bracings (diaphragm bracing) up to bottom waist level to increase the stability. Periodic inspection and maintenance should be conducted to identify and replace the missing members, washers, nuts and bolts. The holes left in the tower members must be filled with bolts and nuts to increase the strength of members. Presently, towers in India are designed for 50, 150 and 500 return periods according to IS-802, and the option of introducing an intermediate return period can also be considered for ultra high voltage lines.

\section{Conclusion}

The results of the detailed studies conducted on the failure of a $765 \mathrm{kV}$ delta-type, single-circuit tower subjected to dust storms indicate that the tower is safe for loads corresponding to the design wind speed $(47 \mathrm{~m} / \mathrm{s})$. The tower members are overstressed even for wind combined with $0.01 \%$ of dust particles, thus causing instability and leading to failure. It is concluded that the wind combined with dust particles significantly affects the tower behaviour. This study emphasizes the need for considering dust particles in storms. It is suggested that in the design 
(a)
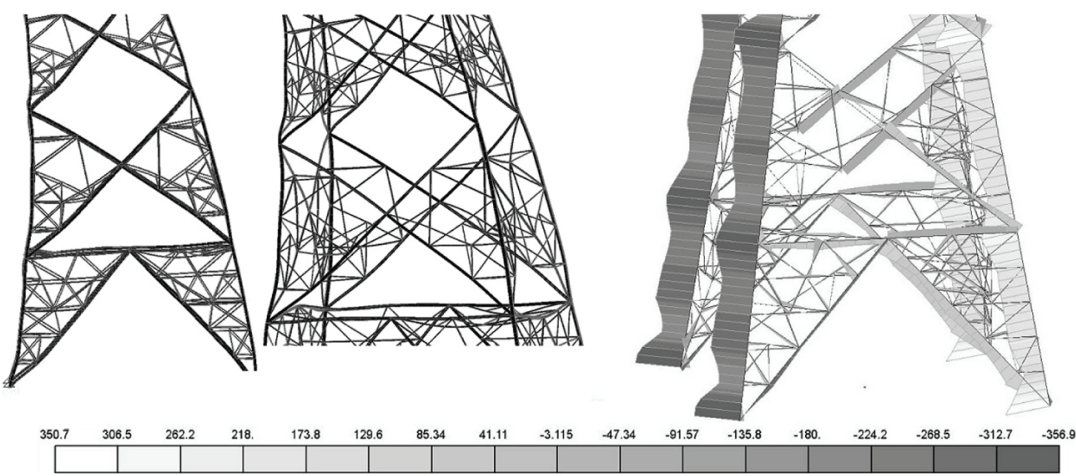

(b)
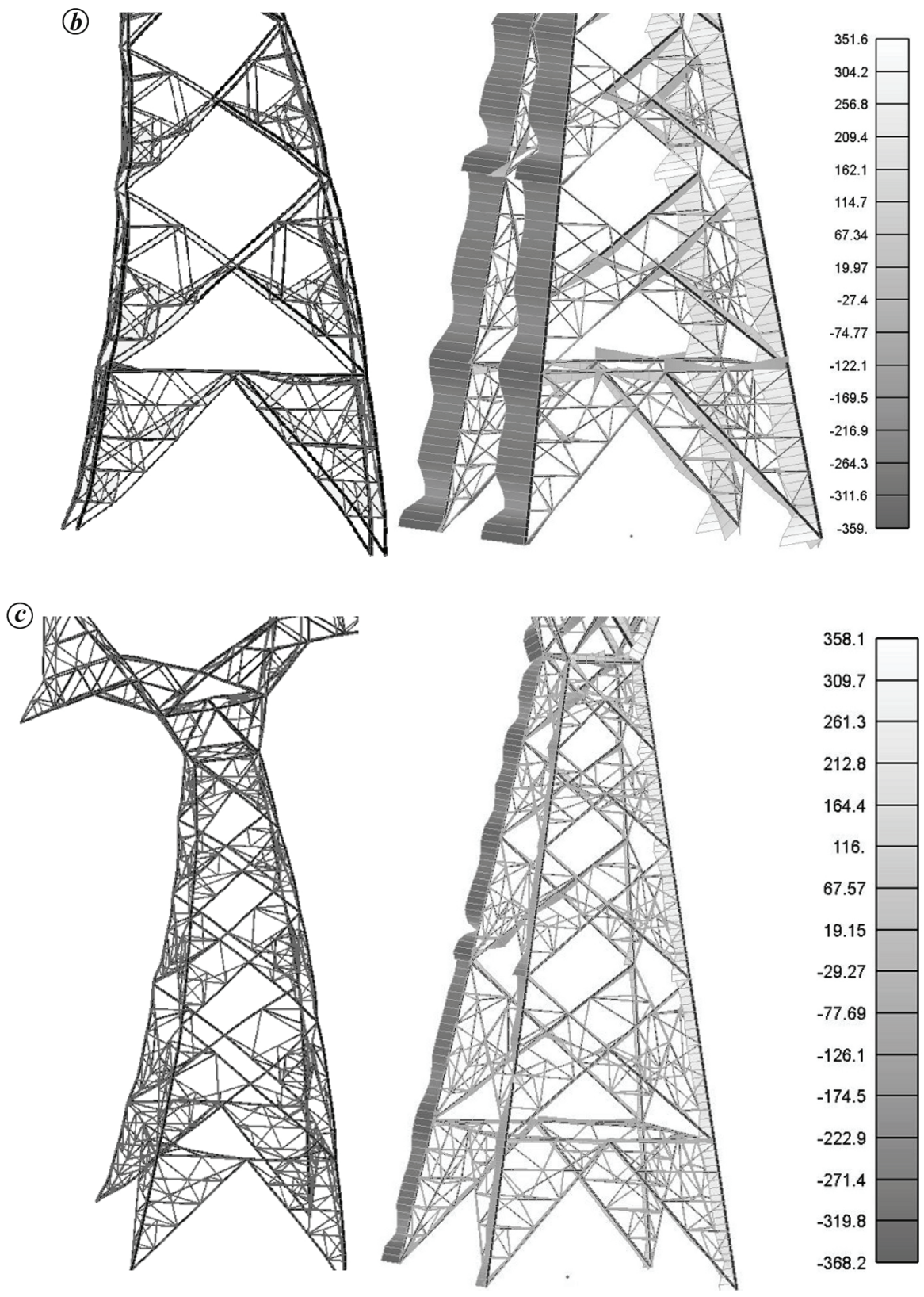

Figure 8. Finite element model failure modes and stress variation in the members at limit load. $\boldsymbol{a}$, Failure at basic tower and stresses in the members: reliability condition with $0.01 \%$ of dust particles in the air. $\boldsymbol{b}$, Failure at basic tower and stresses in the members: reliability condition with $0.02 \%$ of dust particles in the air. $c$, Failure mode and stresses in the members: middle conductor broken condition with $0.01 \%$ of dust particles in the air. 
of TL towers for the northwestern region, the effect of additional loads due to dust storms must be considered.

1. Fu, X. and Li, H. N., Dynamic analysis of transmission tower-line system subjected to wind and rain loads. J. Wind Eng. Ind. Aerodyn., 2016, 157, 95-103.

2. Kikuchi, N., Matsuzaki, Y., Yukino, T. and Ishida, H., Aerodynamic drag of new-design electric power wire in a heavy rainfall and wind. J. Wind Eng. Ind. Aerodyn., 2003, 91(1), 41-51.

3. An, L., Wu, J., Zhang, Z. and Zhang, R., Failure analysis of a lattice transmission tower collapse due to the super typhoon Rammasun in July 2014 in Hainan Province, China. J. Wind Eng. Ind. Aerodyn., 2018, 182, 295-307.

4. Zhang, J. and Xie, Q., Failure analysis of transmission tower subjected to strong wind load. J. Constr. Steel Res., 2019, 160, 271279.

5. Mahmoud, G. H., Tork, B. S. and El-Beshlawy, S. A., Structural capacity and failure mechanisms of transmission towers under high intensity wind loading. IOSR J. Mech. Civ. Eng., 2016, 13(5), 25-33.

6. Fu, X., Wang, J., Li, H. N., Li, J. X. and Yang, L. D., Full-scale test and its numerical simulation of a transmission tower under extreme wind loads. J. Wind Eng. Ind. Aerodyn., 2019, 190, 119-133.

7. Fu, X., Li, H. N. and Wang, J., Failure analysis of a transmission tower subjected to combined wind and rainfall excitations. Struct. Design Tall Spec. Build., 2019, 28(10), 1-19; doi.org/10.1002/ tall.1615.

8. Fu, X. and Li, H. N., Theoretical and experimental studies of the rain load for transmission tower based on single-raindrop impinging force. Int. J. Struct. Stability Dyn., 2019, 19(11), 1950133.

9. Tian, L., Pan, H., Qiu, C., Ma, R. and Yu, Q., Wind-induced collapse analysis of long-span transmission tower-line system considering the member buckling effect. Adv. Struct. Eng., 2019, 22(1), 30-41.

10. Li, J. X., Li, H. N. and Fu, X., Dynamic behaviour of transmission tower-line systems subjected to insulator breakage. Int. J. Struct. Stability Dyn., 2018, 18(3), 1-24.

11. Tian, L., Guo, L., Ma, R., Gai, X. and Wang, W., Full-scale tests and numerical simulations of failure mechanism of power transmission towers. Int. J. Struct. Stability Dyn., 2018, 18(9), 20.

12. Wang, F. Y., Xu, Y. L. and Qu, W. L., Multi-scale failure analysis of transmission towers under downburst loading. Int. J. Struct. Stability Dyn., 2018, 18(2), 1850029.
13. Tapia-Hernández, E., Ibarra-González, S. and De-León-Escobedo, D., Collapse mechanisms of power towers under wind loading. Struct. Infrastruct. Eng., 2017, 13(6), 766-782.

14. Fu, X., Li, H. N. and Li, G., Fragility analysis and estimation of collapse status for transmission tower subjected to wind and rain loads. Struct. Saf., 2016, 58, 1-10.

15. Yang, S. C. and Hong, H. P., Nonlinear inelastic responses of transmission tower-line system under down burst wind. Eng. Struct., 2016, 123, 490-500.

16. Asgarian, B., Eslamlou, S. D., Zaghi, A. E. and Mehr, M., Progressive collapse analysis of power transmission towers. J. Construct. Steel Res., 2016, 123, 31-40.

17. Yang, Q., Xiong, X. F., Wei, Y. N., Wang, J. and Weng, S., Shortterm reliability evaluation of transmission system under strong wind and rain. J. Power Energ. Eng., 2014, 2, 665-672.

18. Li, H. N., Tang, S. Y. and Yi, T. H., Wind-rain-induced vibration test and analytical method of high-voltage transmission tower. Struct. Eng. Mech.: Int. J., 2013, 48(4), 435-453.

19. Xie, Q. and Sun, L., Failure mechanism and retrofitting strategy of transmission tower structures under ice load. J. Constr. Steel Res., 2012, 74, 26-36.

20. IS 875 (Part 3), Indian standard code of practice for design loads (other than earthquake) for buildings and structures, Part 3: wind loads, Bureau of Indian Standards (BIS), New Delhi, 2015.

21. IS 802 (Part $1 / \mathrm{Sec} 1$ ), Indian standard code of practice for use of structural steel in overhead transmission line towers, Part 1: materials, loads and design strengths, Section 1: materials and loads, BIS, New Delhi, 2015.

22. IS 802 (Part $1 / \operatorname{Sec} 2$ ), Indian standard code of practice for use of structural steel in overhead transmission line towers, Part 1: materials, loads and design strengths, Section 2: design strengths, BIS, New Delhi, 2016.

23. ASCE/SEI 10-15, Design of latticed steel transmission structures, American Society of Civil Engineers.

ACKNOWLEDGEMENT. We thank Dr N. Lakshmanan (former Director, CSIR-Structural Engineering Research Centre (SERC), Chennai) and Dr P. Harikrishna (Wind Engineering Laboratory, CSIR-SERC, Chennai) for their guidance and suggestions.

Received 18 August 2020; re-revised accepted 16 June 2021

doi: $10.18520 / \mathrm{cs} / \mathrm{v} 121 / \mathrm{i} 4 / 511-520$ 